CZASOPISMO INŻYNIERII LA¿DOWEJ, ŚRODOWISKA I ARCHITEKTURY JOURNAL OF CIVIL ENGINEERING, ENVIRONMENT AND ARCHITECTURE JCEEA, t. XXXIII, z. 63 (3/16), lipiec-wrzesień 2016, s. 51-58

\author{
Marta CHODYKA ${ }^{1}$ \\ Jerzy NITYCHORUK ${ }^{2}$ \\ Marek ZREDA ${ }^{3}$ \\ Tomasz GRUDNIEWSKI ${ }^{4}$ \\ Zofia LUBAŃSKA ${ }^{5}$
}

\title{
INNOWACYJNA METODA POMIARU WILGOTNOŚCI GLEBY Z ZASTOSOWANIEM NEUTRONÓW KOSMICZNYCH - TRZY LATA FUNKCJONOWANIA CZUJNIKA NA POŁUDNIOWYM PODLASIU
}

\begin{abstract}
Pomiary wilgotności gleby do niedawna były prowadzone punktowo, co miało ograniczenia wynikające z przestrzennych różnic i niejednorodności gleb. Jeśli wykonywane są pomiary punktowe wilgotności gleby, to mogą one być wykorzystane po uśrednieniu, czyli należy zebrać wystarczająco dużą liczbę danych. Aby uzyskać dokładność do trzech punktów procentowych, należy zaprojektować 40 punktów pomiarowych. W artykule przedstawiona została innowacyjna metoda pomiaru wilgotności gleby z zastosowaniem neutronów kosmicznych. Zasadniczą częścią każdego czujnika są dwa liczniki neutronów - licznik z osłoną polietylenową do pomiaru szybkich neutronów oraz nieosłonięty licznik do pomiarów neutronów termicznych. W Stanach Zjednoczonych funkcjonuje system obserwacji wilgotności gleby z zastosowaniem neutronów kosmogenicznych - COSMOS (COsmic-ray Soil Moisture Observing System), który jest wyposażony w 56 stacjonarnych czujników. Pojedyncze czujniki zainstalowane są także miedzy innymi w Kenii, Brazylii, Francji, Szwajcarii i również w Polsce W pracy prezentowane są wyniki badań opracowanych przy wykorzystaniu innowacyjnego czujnika zainsta-
\end{abstract}

${ }^{1}$ Autor do korespondencji / corresponding author: Marta Chodyka, Państwowa Szkoła Wyższa im. Papieża Jana Pawła II w Białej Podlaskiej, Wydział Nauk Ekonomicznych i Technicznych, Zakład Informatyki, ul. Sidorska 95/97, 21-500 Biała Podlaska; tel. 833449907; m.chodyka@dydaktyka.pswbp.pl

2 Jerzy Nitychoruk, Państwowa Szkoła Wyższa im. Papieża Jana Pawła II w Białej Podlaskiej, Wydział Nauk Ekonomicznych i Technicznych, Zakład Budownictwa, ul. Sidorska 95/97, 21-500 Biała Podlaska; ; tel. 833449907; jerzy.nitychoruk@.pswbp.pl

${ }^{3}$ Marek Zreda, Department of Hydrology and Water Resources, University of Arizona, Tucson, Arizona, USA; marek@hwr.arizona.edu

4 Tomasz Grudniewski, Państwowa Szkoła Wyższa im. Papieża Jana Pawła II w Białej Podlaskiej, Wydział Nauk Ekonomicznych i Technicznych, Zakład Informatyki, ul. Sidorska 95/97, 21-500 Biała Podlaska; tel 833449908; knt@pswbp.pl

5 Zofia Lubańska, Państwowa Szkoła Wyższa im. Papieża Jana Pawła II w Białej Podlaskiej Wydział Nauk Ekonomicznych i Technicznych, Zakład Informatyki, ul. Sidorska 95/97, 21-500 Biała Podlaska; tel. 833449908; z.lubanska@dydaktyka.pswbp.pl 
lowanego w Polsce w miejscowości Derło. Dane pozyskane w trakcie trzech rocznych cykli pomiarowych dobrze korelują z obserwowanymi opadami deszczu i śniegu. Cykle pomiarowe obejmują okres od kwietnia do końca marca. Szczegółowa analiza zarejestrowanych w tym okresie danych wskazuje na przyczyny zróżnicowania wilgotności gleby. Okazuje się, że czujnik może być wykorzystywany do identyfikacji okresu występowania pokrywy śnieżnej zalegającej na danym terenie.

Słowa kluczowe: wilgotność gleby, neutrony kosmiczne, COSMOS, metoda pomiarowa

\section{Wprowadzenie}

Wilgotność gleby jest związana z bilansem biomasy i energii wymienianej pomiędzy powierzchnią ziemi i atmosferą. Ma ona wpływ na takie procesy jak: odpływ powierzchniowy, infiltracja, parowanie, transpiracja, wegetacja roślin, a także na pogodę i klimat.

Pomiary wilgotności gleby do niedawna były prowadzone punktowo, co miało ograniczenia wynikające z przestrzennych różnic i niejednorodności gleb. Jeśli wykonujemy pomiary punktowe wilgotności gleby, to mogą one być wykorzystane po uśrednieniu, czyli musimy zebrać wystarczająco dużą liczbę danych. Aby uzyskać dokładność do trzech punktów procentowych, należy zaprojektować 40 punktów pomiarowych. Zreda i in. zaproponowali nową metodę pomiaru wilgotności gleby wykorzystującą promieniowanie kosmiczne [1]. Zaprojektowane przez nich nowe czujniki mierzą wilgotność gleby w promieniu ok. $300 \mathrm{~m}$, co skutecznie zastępuje całą sieć pomiarową niezbędną do wyliczenia średniej wilgotności gleby.

Wiktor Hess odkrył promieniowanie kosmiczne w 1912, za co otrzymał Nagrodę Nobla w dziedzinie fizyki w 1936 r. Hess stwierdził, że intensywność jonizacji promieniotwórczej wzrasta wraz z wysokością nad powierzchnią Ziemi, co wskazuje na źródło promieniowania poza Ziemią [2]. To promieniowanie Robert Millikan nazwał w latach 20. XX w. ,promieniowaniem kosmicznym”. Kolejnym ważnym krokiem w badaniu promieniowania kosmicznego było stwierdzenie, że intensywność niskoenergetycznych neutronów promieniowania kosmicznego zależy głównie od zawartości wodoru w środowisku [3, 4]. Z kolei Hendrick i Edge wykazali, że intensywność „szybkich” neutronów nad powierzchnią ziemi zależy od zawartości wilgoci w glebie [5], co zostało wykorzystane do jej pomiaru $[6,7]$. Wodór posiada największą siłę hamowania i usuwania neutronów [1,8], co stanowi podstawę pomiaru wilgotności gleby metodą neutronów kosmogenicznych. Większa ilość wody w glebie skutkuje większym wyhamowaniem neutronów, powodując zmniejszenie ich ilości nad jej powierzchnią. Mniejsza ilość wody w glebie ma efekt przeciwny. Zreda i in., w 2008 r. umieścili czujniki mierzące promieniowanie kosmiczne ponad powierzchnią ziemi, co pozwoliło na skuteczny pomiar wilgotności gleby [1]. 
W kolejnych badaniach ich czujnik [9] zmierzył wilgotność gleby w promieniu $300 \mathrm{~m}$, co uczyniło go bardzo skutecznym.

Prof. Zreda z zespołem, założył w USA system obserwacji wilgotności gleby za pomocą neutronów kosmogenicznych - COSMOS (COsmic-ray Soil Moisture Observing System), który jest wyposażony w 56 stacjonarnych czujników (rys. 1).

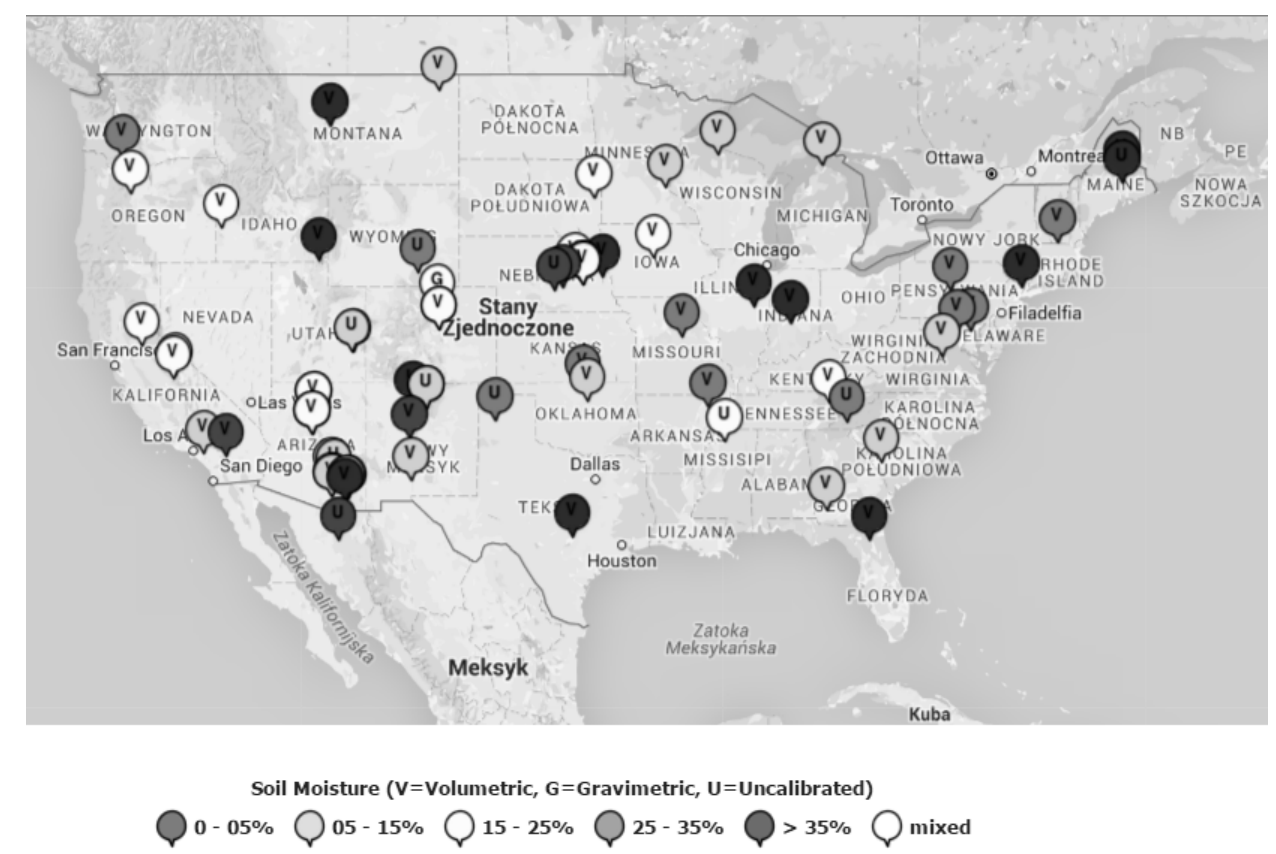

Rys. 1. Umiejscowienie elementów projektu COSMOS na terenie USA

Fig. 1. COSMOS sites in the U.S.

Pojedyncze czujniki zainstalowane są miedzy innymi w Kenii (2), Brazylii (1), Francji (1), Szwajcarii (1) i również w Polsce (1 - rys. 2). Szczegółowe informacje o czujnikach i ich lokalizacjach można uzyskać na stronie internetowej http://cosmos.hwr.arizona.edu, gdzie są również dostępne dane pomiarowe, dostarczane bezpośrednio poprzez system satelitarny.

Zasadniczą częścią każdego czujnika są dwa liczniki neutronów - licznik z osłoną polietylenową do pomiaru szybkich neutronów oraz nieosłonięty licznik do pomiarów neutronów termicznych.

Dane z pierwszego licznika służą do pomiaru wilgotności gleby, natomiast dane $\mathrm{z}$ drugiego do pomiaru ilości wody na powierzchni gruntu, w śniegu, $\mathrm{w}$ roślinach itp. Czujniki zasilane są $\mathrm{z}$ akumulatorów stale ładowanych z paneli słonecznych. Dane pomiarowe są wysyłane przez modem satelitarny sieci Iridium do centralnego serwera systemu COSMOS, gdzie po przetworzeniu są umieszcza- 
ne na ogólnodostępnej stronie internetowej http://cosmos.hwr.arizona.edu, z której można uzyskać dane o liczbie zmierzonych neutronów szybkich, liczbie neutronów termicznych, ciśnieniu atmosferycznym oraz względnej wilgotności i temperaturze wewnątrz urządzenia.

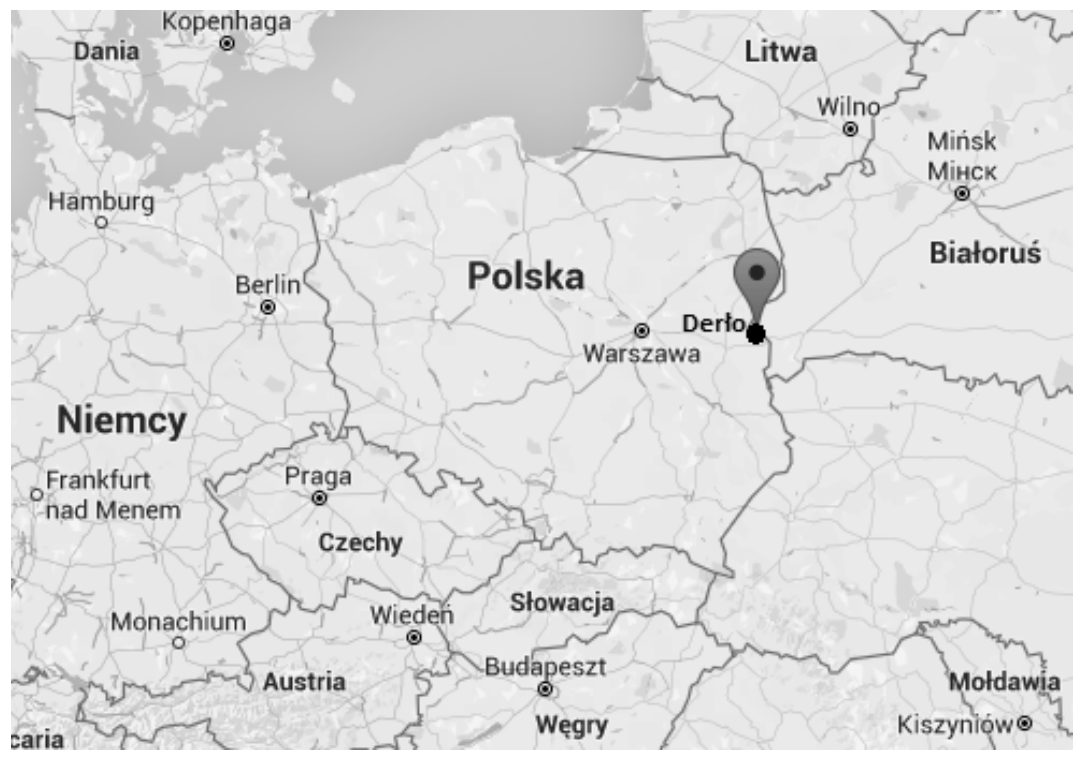

Rys. 2. Lokalizacja czujnika Derło we wschodniej Polsce

Fig. 2. Location of the probe Derło in eastern Poland

Jednym z pierwszych założonych czujników tego typu jest czujnik San Pedro, który działa nieprzerwalnie od lipca 2007 r. i jak dotąd, poza wymiana baterii, nie wymagał interwencji serwisu [8].

\section{Wyniki pracy czujnika Derło w Polsce}

Pierwszy, i jak dotychczas jedyny w Polsce czujnik do pomiaru wilgotności gleby za pomocą pomiaru neutronów kosmicznych został zainstalowany w Derle, na południowym Podlasiu w dniu 15 kwietnia 2013 r. (rys. 3).

Każdy czujnik wymaga ręcznej kalibracji, również czujnik w Derle został skalibrowany przy użyciu 95 próbek gleby, dla których wykonano oznaczenie wilgotności metodą suszenia próbek w piecu i obliczania wilgotności z różnicy wartości wagowej próbki suchej i wilgotnej.

Dotychczas udało się uzyskać trzy roczne cykle pomiarowe, które można dobrze korelować z obserwowanymi opadami deszczu i śniegu (rys. 4). 


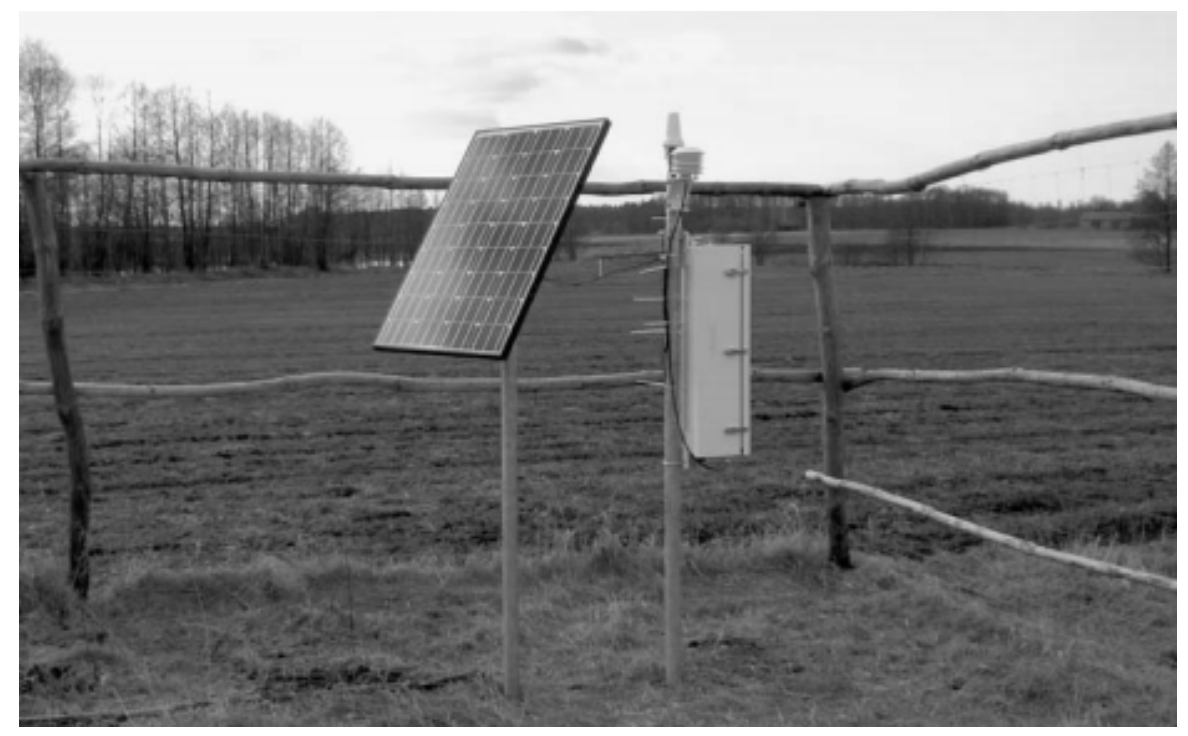

Rys. 3. Czujnik Derło. Biała skrzynka po prawej stronie zawiera dwa liczniki neutronów każdy z własnym modułem impulsów, rejestrator danych, modem satelitarny i akumulator

Fig. 3. Probe Derło. The white box on the right side contains two neutron counters with a neutron pulse module each, a data logger, a satellite modem and a rechargeable battery

Cykle obejmują okres od kwietnia do końca marca, gdyż w kwietniu zainstalowano czujnik, który rozpoczął wówczas pomiary. Cykl najstarszy 2013/2014 jest najpełniejszy, w pozostałych są luki pomiarowe przypadające na okres zimowy, które są trudne do wyjaśnienia. Mimo pewnych luk można wysunąć ciekawe wnioski z trzech cykli obserwacji.

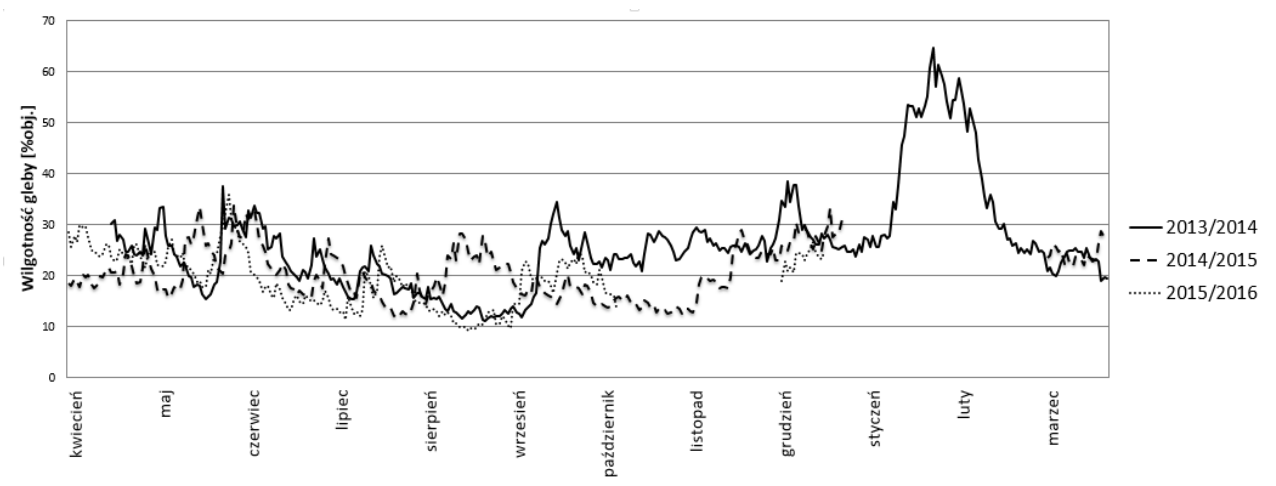

Rys. 4. Średnie, 12-godzinne wartości wilgotności gleby, zmierzone przez czujnik Derło w okolicach Białej Podlaskiej od 04.2013 do 03.2016

Fig. 4. 12-hour moving average values of soil moisture at the COSMOS site Derło near Biała Podlaska, between April 2013 and March 2016 
Szczególnie dobrze zostały odwzorowane opady śniegu i zaleganie pokrywy śnieżnej w okresie zimy 2013/2014. Na wykresie wilgotności gleby z czujnika Derło, obecność śniegu pokrywa się z wartościami wilgotności ponad $45 \%$. Zimy 2014/2015 i 2015/2016 były bezśnieżne, dlatego brak jest tu tak dużych wartości, ale i brak jest pomiarów. Po opadach śniegu zauważalny jest gwałtowny spadek ilości szybkich neutronów, podczas gdy w tym samym czasie wzrosła intensywność neutronów termicznych, co sugeruje, że przy użyciu obu typów neutronów można odróżnić śnieg od wody w glebie. Zliczona ilość szybkich neutronów po opadzie śniegu pozostaje niemal bez zmian, podczas gdy ilość neutronów termicznych powoli maleje. Stosunek neutronów szybkich do termicznych jest dobrym wskaźnikiem pojawienia się pokrywy śnieżnej. Podwyższone wartości wilgotności gleby mają miejsce we wszystkich cyklach na wiosnę, w maju, kiedy wartości przekraczają $30 \%$. Następnie wilgotność spada i w okresie lata jest najniższa osiągając kilkanaście procent w latach 2013 i 2015. W roku 2014 sierpień był wyjątkowo deszczowy, co przełożyło się na wilgotność gleby. Z kolei w roku 2013 wilgotny był wrzesień i pozostała część jesieni, co dobrze widać porównując z rokiem 2014.

Dobrze zauważalne są generalne trendy, które są charakterystyczne dla wszystkich trzech okresów pomiarowych we wszystkich sezonach obserwacyjnych. Duże opady deszczu skutkują gwałtownym wzrostem wilgotności gleby, po czym następuje stopniowe obniżanie tych wartości związane z osuszaniem gleb. Jednak poszczególne miesiące mogą się różnić intensywnością opadów, co przekłada się na zmiany wilgotności. Ciekawym jest, że różnice w ilości śniegu w zimie nie przekładają się wyraźnie na wilgotność gleby na wiosnę. Zima 2013/2014 była znacznie bardziej śnieżna niż pozostałe. Nie wiadomo jednak, jak śnieżna zima może przełożyć się na ilość opadów w okresie lata? W okresie zimowym 2013/2014, opady śniegu miały miejsce w styczniu i lutym, co zostało zauważone w sygnale neutronów.

\section{Wnioski}

Metoda badania wilgotności gleby za pomocą neutronów kosmogenicznych może być wykorzystywana przy różnorodnych glebach oraz na częściowo zabudowanych terenach miejskich. Wilgotność gleby nie jest uzależniona od jej składu, a sama metoda jest nieinwazyjna i umożliwia podjęcie badań w wielu innych dziedzinach między innymi w: meteorologii, klimatologii, hydrologii, ekologii, teledetekcji, rolnictwie i leśnictwie, czyli wszędzie tam gdzie wilgotność gleby jest istotnym składnikiem środowiskowym.

Pierwszy tego typu czujnik pomiarowy w Polsce pracuje w sposób ciągły od 3 lat. Na podstawie zarejestrowanych za jego pomocą danych można badać przyczyny zróżnicowania wilgotności gleby. Okazuje się, że czujnik bazujący na pomiarze liczby neutronów kosmogenicznych może być z powodzeniem wykorzystywany do identyfikacji okresów występowania pokrywy śnieżnej. 
Obszar Polski wschodniej, położony w strefie wpływów klimatu kontynentalnego i morskiego jest szczególnie ciekawy do prowadzenia pomiarów wilgotności gleby. Po wstępnej serii pomiarowej, która zakończyła się sukcesem, przewiduje się zwiększenie liczby czujników i objęcie monitoringiem większych obszarów kraju.

Planowane jest także przyłączenie wszystkich czujników w Polsce systemu COSMOS, co zdaniem autorów korzystnie wpłynie na postęp w prowadzonych badaniach atmosfery - mapy pogody, śledzenie zmian klimatu, badań hydrosfery - bilanse wilgotności gleby i jej wpływ na zmiany w środowisku, przewidywanie suszy i powodzi, dostęp wody dla działalności człowieka, szacowanie ewapotranspiracji, szacowanie zagrożenia osuwiskowego; badań biosfery -zmiany biomasy, stres wodny roślin.

\section{Literatura}

[1] Zreda M., Desilets D., Ferré T. P. A. \& Scott R. L.: Measuring soil moisture content non-invasively at intermediate spatial scale using cosmicray neutrons. Geophysic. Res. Lett., 35. L21402, 2008.

[2] Hess V.F.: Uber Beobachtungen der durchdringenden Strahlung bei sieben Freiballonfahrten. Physikal. Z., 13. 1912, 1084-1091.

[3] Fermi E.: Artificial radioactivity produced by neutron bombardment, Nobel Lectures, Physics 1922-1941, Amsterdam, Elsevier Publishing Company. 1938, 414-421.

[4] Bethe H.A., Korff S.A. \& Placzek G.: On the interpretation of neutron measurements in cosmic radiation. Physic. Rev., 57. 1940, 573-587.

[5] Hendrick L.D. \& Edge R.D.: Cosmic-ray neutrons near the Earth. Physic. Rev. Ser. II, 145. 1966, 1023-1025.

[6] Kodama M., Nakai K., Kawasaki S. \& Wada M.: Application of cosmic-ray neutron measurements to the determination of the snow-water equivalent. J. Hydrometeorol., 41. 1979, 85-92.

[7] Kodama M., Kudo S. \& Kosuge T.: Application of atmospheric neutrons to soil moisture measurement. Soil Sci., 140. 1985, 237-242.

[8] Zreda M., Shuttleworth W.J., Zeng X., Zweck C., Desilets D., Franz T. \& Rosolem R.: COSMOS: the COsmic-ray Soil Moisture Observing System. Hydrol. and Earth System Sci., 16. 2012, 4079-4099.

[9] Desilets D., Zreda M. \& Ferre T.: Nature's neutron probe: Landsurface hydrology at an elusive scale with cosmic rays. Water Resour. Res., 46. W11505, 2010. 


\section{AN INNOVATIVE METHOD OF MEASURING SOIL MOISTURE USING COSMIC-RAY NEUTRONS - THREE YEARS OF WORK OF THE SENSOR IN SOUTHERN PODLASIE}

\section{S u m m a r y}

Measurements of soil moisture until recently were conducted by checking particular spots, which had its limitations due to soil spatial differences and heterogeneity. If spot checks are made to measure soil moisture, the gathered data can be used only after being averaged, which means collecting a sufficiently large number of data. To get results that would be accurate to within three percent, one must conduct 40 check points. The article presents an innovative method of measuring soil moisture by using space neutrons, which gives new opportunities. The main part of each sensor are two neutron - counters covered with polythene to measure fast neutrons, and an uncovered counter for measuring thermal neutrons. The United States has a system of measuring the soil moisture that uses space genic neutrons - COSMOS (Cosmic-ray Soil Moisture Observing System), which is equipped with 56 stationary sensors. Individual sensors are also installed, among others, in Kenya, Brazil, France, Switzerland and in Poland. The authors wish to present the results of innovative sensing research done in Derło, Poland. The conclusions have been based on three annual cycles of measurement that can be well correlated with the observed rainfall and snow. The cycles cover the period from April to the end of March (2013 - 2016). The first sensor in Poland has already taken three season measurements, on the basis of which one can draw interesting conclusions about the reasons for soil moisture diversity. It turns out that the sensor can also be used to determine the period of snow.

Keywords: soil moisture, cosmic-ray neutrons, COSMOS, measuring method

DOI:10.7862/rb.2016.185

Przestano do redakcji: $30.06 .2016 r$.

Przyjęto do druku: 30.11.2016 r. 